\title{
Consideraciones liberales sobre la Enseñanza Religiosa Escolar
}

David A. Yáñez Baptista'

\section{Resumen}

La educación neutral que propugnan los detractores de la Enseñanza Religiosa Escolar (ERE) ni existe ni es deseable; no es sino una idea oriunda de una concepción anticuada del liberalismo. Por desgracia, quienes defienden la ERE también asumen, a su modo, ese liberalismo. Por contra, este artículo presenta un liberalismo distinto, en el que sí cabe que la escuela española tenga un alma católica. Lejos de todo nacionalcatolicismo, la escuela debe entregar a las nuevas generaciones su herencia cultural cristiana, imprescindible para proyectarse hacia el futuro. Por eso, estas páginas concretan en qué sentido la ERE es un derecho educativo esencial del alumnado.

\section{Palabras clave}

Liberalismo, ERE, derecho, deber, cultura.

\section{Introducción}

Bastante se ha hablado de la nueva ley de educación como para seguir contribuyendo con estas páginas a la disensión pública. No me interesa discutir la nueva ley - en este caso, en lo que respecta a la enseñanza religiosa escolar - en cuanto fenómeno político actual. Como tal es de suyo superficial. Entiéndase bien: toda política es superficial; necesita nutrirse, como la parte visible de las plantas, desde sus raíces interpretativas más profundas. Y por lo que res-

1 Doctorando en Filosofía de la Universidad Complutense de Madrid y estudiante de Baccalaureatus en Ciencias Religiosas en el Instituto San Pío X (Madrid). 
pecta a su actualidad, la política tampoco se entiende ni se valora adecuadamente sin mirar al pasado y al porvenir. Por eso conviene alejarse tanto de la actualidad como de la política para poder pensar la nueva legislación de la asignatura de religión más amplia y hondamente; a saber, desde una perspectiva histórica y filosófica. Este es el punto de vista sugerido en el presente artículo.

El problema más grave y urgente y que debiera tenerse en cuenta para la legislación educativa en materia religiosa es el siguiente: el desconocimiento del patrimonio cultural nacional y del europeo - tesoro común de las sociedades occidentales-. Esta ignorancia pone en peligro la identidad cristiana de nuestra sociedad y agrava la secularización con la indiferencia y el secularismo, lo que impide aprovechar el pasado para la construcción del futuro² . La legislación educativa en materia religiosa debería tratar de frenar esta pérdida de identidad. Sin embargo, los defensores de la enseñanza religiosa escolar se limitan a discutir en balde en términos liberales. Gane quien gane, se trata de una discusión condenada al fracaso, pues el liberalismo decimonónico del que se parte no es un planteamiento que esté a la altura de los tiempos.

\section{El problema liberal}

La palabra "liberalismo", cuyo significado varía de boca en boca según quien la pronuncie, en una de sus acepciones se refiere a una necesaria neutralidad del Estado. En una sociedad plural como la actual - dicen estos liberales - el Estado tiene que mantenerse al margen de la promoción de cualquier forma de vida. Su función es la de garantizar, desde la neutralidad axiológica, la libertad de los ciudadanos. Ellos han de escoger la vida que quieren llevar de acuerdo con los valores que más estiman.

Si nos atenemos a los valores religiosos, el liberalismo se convierte en el campo de batalla entre dos bandos.

2 Véase la distinción entre secularización y secularismo en Evangelii Nuntiandi (n. 55). Pablo VI, Exhortación apostólica "Evangelii Nuntiandi" acerca de la evangelización del mundo contemporáneo, Ciudad del Vaticano 1975. A partir de ahora EN. En este caso EN 55. 
Por una parte, hay un bando que se ampara en la neutralidad estatal como garantía de la libertad religiosa de los ciudadanos. Cada cual tendría derecho a vivir conforme a sus propias "convicciones" religiosas y el Estado aconfesional debería proteger esas formas de vida sin imponer ninguna. De este modo, este planteamiento permitiría la existencia de colegios concertados y privados de carácter confesional. Igualmente, tiene que haber una asignatura de religión optativa en la escuela pública. Este bando fundamenta sus reivindicaciones en la Constitución, recordando que "los poderes públicos garantizan el derecho que asiste a los padres para que sus hijos reciban la formación religiosa y moral que esté de acuerdo con sus propias convicciones" (art. 27.3). Por eso mismo, contando con las "creencias" religiosas de la sociedad, los poderes públicos "mantendrán las consiguientes relaciones de cooperación con la Iglesia Católica y las demás confesiones" (art. 16.3).

Por otra parte, el bando contrario insiste en la neutralidad del Estado. Se apoya en la Constitución, la cual establece que "ninguna confesión tendrá carácter estatal” (art. 16.3). Aplicando a rajatabla esta parte del artículo constitucional en todas las instituciones de la vida social, sería preciso eliminar la asignatura religión de la escuela pública, e incluso suprimir la religiosa concertada. Como mucho, sólo quedaría lugar para la escuela religiosa privada. Relegada de esta forma al ámbito privado, en modo alguno se atentaría contra la libertad religiosa que se reconoce en nuestra Constitución (art. 16.1). Ahora bien, los que así piensan en realidad no aceptan toda nuestra Constitución. Preferirían tener un Estado laico en vez de aconfesional.

Los primeros insisten más en el ejercicio de nuestras libertades; por eso piden que el Estado las ampare y fomente en el seno de la vida pública, sin que el mismo Estado se vincule con ninguna. En cambio, los segundos hacen lo contrario; acentúan la neutralidad del poder público y de toda institución, considerando que cualquier opción religiosa que trascienda el ámbito estrictamente privado se está entrometiendo en la vida colectiva.

No hace falta tomar partido a favor de unos para darse cuenta de los errores de los otros - o lo que es peor, de sus mentiras-. La manipu- 
lación ideológica es el patrimonio de los extremismos. Así, desde el extremo anticlerical se insiste en presentar la Transición española como si fuera una apariencia. Para subrayar una supuesta continuidad encubierta de la dictadura, se habla del "régimen del 78". Por lo mismo, los Acuerdos internacionales entre el Estado español y la Santa Sede también perpetuarían el régimen franquista. Pero si somos veraces, reconoceremos que la democracia liberal española nunca ha sido ni es un Estado nacionalcatólico. Los mencionados Acuerdos de 1979 modificaron la situación de la educación religiosa española del Concordato de 1953. La asignatura de religión pasó de ser obligatoria a ser optativa, garantizando siempre el derecho a recibirla. Y a diferencia de lo que ocurría durante el gobierno franquista, esta asignatura excluye el culto y los ejercicios piadosos, concibiendo la enseñanza religiosa escolar con un rigor académico equiparable al de las demás disciplinas fundamentales ${ }^{3}$.

Solemos olvidar que los profesores de religión imparten una asignatura académica. No dan catequesis ${ }^{4}$. El lugar de la catequesis es la comunidad eclesial, no la escuela; aunque ambos coincidan cuando se trata de la escuela católica, son ámbitos diferentes. Los destinatarios de la catequesis también son distintos: en un caso, creyentes (o, al menos, en búsqueda y en proceso de conversión); en el otro caso, son simplemente alumnos, independientemente de su fe. Además, la finalidad de la catequesis es la iniciación y la maduración de la fe, pero el profesor de religión no pastorea la fe y en modo alguno evalúa el establecimiento y la intensificación de la relación personal del alumno con Dios. La misión del profesor es previa: la de enseñar a sus alumnos en qué consiste la religión, cuál es su explicación antropológica, qué importancia histórica ha tenido, de qué forma se plasma en las instituciones, cuál es el mensaje que transmite, etc.

3 Cf. Conventiones Inter Apostolicam Sedem et Nationem Hispanam (Acuerdos internacionales entre el Estado Español y la Santa Sede). 3 de enero de 1979. Ciudad del Vaticano 1979. Art. 2 y 4 y Comisión Episcopal de Enseñanza y catequesis, Orientaciones Pastorales sobre la Enseñanza Religiosa Escolar. Su legitimidad, carácter propio y contenido, Madrid 1979. A partir de ahora Orientaciones pastorales. En este caso Orientaciones pastorales n. 51.

4 Cf. Orientaciones pastorales, nn. 59-70. 
Habiendo distinguido la catequesis de la asignatura de religión, también hay que aclarar que esta última no es un "adoctrinamiento", en el sentido peyorativo que hoy le damos a esta palabra. El objetivo de la materia de religión es justo el contrario: insertar al alumno lúcidamente en la tradición cultural de su sociedad para que viva en ella de forma crítica, especialmente en lo que respecta al sentido último de la vida con todas sus implicaciones éticas ${ }^{5}$. En cuanto a la perversión de esta finalidad, el riesgo de que la asignatura degenere en una forma de "adoctrinamiento" no es un riesgo exclusivo de la clase de religión. El profesor de religión puede adoctrinarnos tanto como cualquier otro: como el de historia cuando falsea el pasado a su gusto o el de filosofía cuando encumbra ciertas ideas sociopolíticas. El problema no está en la asignatura, sino en la formación y catadura moral del docente. Por otra parte, es sorprendente el sentido negativo que ha adquirido la palabra "adoctrinar". Antes significaba "enseñar una doctrina", fuera religiosa o filosófica. Pero ahora este vocablo se ha convertido en un sinónimo de "imponer", con lo que el adoctrinamiento evangelizador se confunde con un proselitismo intransigente. Por eso se piensa que mientras que el catequista adoctrina - es decir, impone-el profesor tiene que hacer todo lo contrario. Y así nos vamos al otro extremo de la imposición: “ El profesor no nos debe convencer de nada, tiene que ser neutral!", nos dicen. Pero convencer sería lo más natural, si concedemos que enseñar implica, no sólo dar cuenta de algo, sino dar cuenta y razón. $\mathrm{Y}$ las razones convencen. No querer convencer significa no querer tener razón y tampoco querer concederla. Por desgracia, a todo el que quiera convencer le acusarán de querer imponer. Ahora bien, como la neutralidad docente es imposible, como mostraré más adelante, y como está prohibido convencer, la consecuencia es evidente: es el triunfo del relativismo.

\section{Confusión de derechos}

Conste que, si bien defiendo la presencia de la asignatura de religión en la escuela, esto no significa que esté de acuerdo con uno de los bandos "liberales" en liza. Como dijimos, los padres de ese bando de-

5 Cf. Orientaciones pastorales, nn. 13-15. 
fienden la asignatura empuñando el derecho de que la educación de sus hijos concuerde con sus "convicciones". Las de los padres, claro. Para ello se amparan en el artículo 27.3 de la Constitución, que reproduce la reivindicación del Pacto Internacional de Derechos Civiles y Políticos: "respetar la libertad de los padres y, en su caso, de los tutores legales, para garantizar que los hijos reciban la educación religiosa y moral que esté de acuerdo con sus propias convicciones". Se entiende que este artículo se refiere al derecho de los padres a escoger, no sólo una escuela católica para sus hijos, sino también la asignatura de religión. Así se interpreta en conformidad con los Acuerdos del 79 , según los cuales "por respeto a la libertad de conciencia, dicha enseñanza no tendrá carácter obligatorio para los alumnos. Se garantiza, sin embargo, el derecho a recibirla". Esto mismo escribieron los obispos de las Orientaciones Pastorales sobre la Enseñanza Religiosa Escolar (n. 22), en consonancia con el Concilio Vaticano II. En la Declaración Dignitatis humanae (n. 5) no sólo se habla del "derecho de los padres a elegir con verdadera libertad las escuelas"; se añade que "se violan, además, los derechos de los padres si se obliga a los hijos a asistir a lecciones escolares que no correspondan a la convicción religiosa de los padres".

Por mi parte, considero que ese añadido es justamente lo que urge corregir. La libertad y el derecho de los padres sólo deberían referirse a la posibilidad que tienen los padres de escoger para sus hijos una escuela católica, es decir, un colegio concertado o privado animado en su misión educativa por un sentido cristiano ${ }^{6}$. Pero en modo alguno deberíamos incluir dentro de esos derechos de los padres la elección de la asignatura de religión?.

6 En tal caso, el carácter académico de todas las asignaturas -incluida la de religión- se complementaría con toda una serie de actividades eclesiales acordes con las "convicciones" de los padres: oraciones matutinas, misas, catequesis, convivencias, obras caritativas, etc. A este derecho se alude en la Declaración Gravissimus educationis, en el que la Iglesia, refiriéndose a los padres, defiende su "libertad absoluta en la elección de las escuelas" (n. 6). Concilio Vaticano II, Declaración "Gravissimum educationes" sobre la educación cristiana, Ciudad del Vaticano 1965. A partir de ahora GE.

7 Lo mismo podemos decir del niño que ha crecido y ha ido tomando posesión del uso de la razón, haciendo suyo ese supuesto derecho que los padres empiezan ejerciendo por él. 
En Gravissimus educationis (n. 7) se alude a "una educación conforme a los principios religiosos y morales de las familias", la cual ha de estar presente "en todas las escuelas". Dado que se está hablando de todas las escuelas - por tanto, de las públicas-, se entiende que la educación defendida se corresponde con la asignatura de religión. Pero si ésta se distingue de la catequesis, ¿por qué hay que defender la libertad de las familias para escoger para sus hijos una educación a la carta? ¿No se ve que esta libertad es peligrosa? Si los padres son los que deciden qué es lo que estudian sus hijos, las consecuencias pueden ser fatales. Cegados por el utilitarismo y el practicismo, por prejuicios ideológicos o por simple ignorancia, podrían excluir de la educación materias imprescindibles como la filosofia, las artes o la misma religión. ¿Se imaginan que los padres eligieran que sus hijos no estudiasen ciencias porque tienen convicciones creacionistas y terraplanistas? ¡Qué escandalo! Sin embargo, no hay ningún problema cuando los padres impiden que sus hijos estudien religión. Y no se me acuse de omitir el problema contrario: que los niños estudien religión por culpa de la atmósfera religiosa opresiva de su hogar. Tan indeseable es lo uno como lo otro ${ }^{8}$. En ambos casos, con una asignatura de religión meramente optativa, los alumnos están desprotegidos frente a sus padres, que vulneran el derecho constitucional de sus hijos a un desarrollo educativo pleno (cf. art 27.2).

No equiparemos la elección de religión con otras elecciones curriculares para restarle gravedad al asunto. El carácter optativo de ciertas materias del segundo ciclo de Secundaria y en Bachillerato responde a la necesidad de itinerarios acordes con las posibilidades, necesidades e intereses de los alumnos. Pero la religión, como empapa toda nuestra historia, nuestra literatura y todas las artes, nuestros valores e instituciones y nuestras costumbres no debería ser una asignatura a elegir; al contrario, como la historia o la lengua tendría que ser obligatoria, porque sin ella el alumno no sabe quién es, ni cómo se ha configurado el mundo en el que vive.

8 Aunque una cosa es menos liberadora que otra. En un caso, se priva a los estudiantes del conocimiento de la religión, sin poder escapar de los prejuicios familiares; en el otro caso, una verdadera comprensión del fenómeno religioso curaría al alumno de la insalubre piedad del ámbito familiar. 
Al igual que la ciencia es un producto cultural específicamente europeo y occidental, nuestra sociedad actual posee un acervo cultural en buena medida heredado de la base cristiana de nuestra civilización. Sin embargo, mientras los alumnos tienen que estudiar ciencias obligatoriamente en Primaria y ESO, parece que de la religión podemos prescindir. Esto impide que nos apropiemos de nuestra tradición cultural. Por eso necesitamos que haya en la escuela, como transmisora de la cultura, una enseñanza de religión que no esté sujeta a las arbitrariedades ideológicas de los padres. Esta enseñanza religiosa resulta todavía más imperiosa si contamos con quienes quieren destruir nuestra herencia cultural de ideas y valores occidentales. Si "cultura" significa "lo que hay que cultivar", ¿cómo van a germinar las semillas de la historia en las generaciones futuras si ni siquiera se cultivan en la escuela? Así no hace falta ni arrancar, con lo cual es mucho más fácil manipular.

Quienes defienden la ERE en el marco anticuadamente "liberal" insisten demasiado en los derechos de los padres y se olvidan de sus obligaciones. Pero el derecho de la ERE no es de los padres, sino de los hijos: el derecho a recibir en la escuela la herencia cultural que les corresponde para invertir con ella en el futuro, cuando los alumnos empiecen a vivir de forma creadora en la sociedad. Por eso convendría que los padres dejaran de prestar tanta atención a sus derechos y se acordasen más de sus deberes. La libertad no sirve para elegir cualquier cosa con la que simpaticemos ni para rechazar lo que desdeñamos; la libertad verdadera no significa capricho sino responsabilidad. Ejerciéndola somos conscientes del deber que es preciso cumplir. El alumno tiene derecho a una educación plena e integral - que como tal, incluye la ERE-y los padres tienen el deber de proporcionársela. Lo demás es una confusión de derechos?.

9 Sobre esta confusión, pero sin centrarse en la ERE: cf. A. Castillo, "La libertad de los padres y la de los hijos", El Asterisco (25-04-2019). Podrían citarse otros artículos suyos que complementarían los temas aquí tratados. No obstante, la deuda de estas páginas con estos artículos es nula; la indudable influencia no es la de la letra - pese a ser la única registrable- sino la de la vida. 


\section{El pluralismo religioso}

¿Cuál sería esa enseñanza religiosa obligatoria a la que los alumnos tienen derecho? No concibo otra que la católica, dada la tradición cultural de la sociedad española. Imagínense que en las escuelas españolas se enseñase gramática alemana en Lengua y la restauración Meiji en Historia. Igual de absurdo sería dedicar al taoísmo la clase de religión. La enseñanza del catolicismo debería ser obligatoria para todos los que viven en España y para los que desde fuera vienen a formar parte de su proyecto histórico. La razón es clara: sólo podemos proyectarnos hacia el futuro con acierto si nos apoyamos en las posibilidades que nos brinda el pasado. Nuestra capacidad crítica en la sociedad actual - es decir, de cambio y progreso-sólo es efectiva cuando nos situamos lúcidamente en nuestra tradición cultural ${ }^{10}$.

Por supuesto, la clase de religión católica debe incluir en su temario unos apartados dedicados al judaísmo, el islam y las Iglesias reformadas. Al judaísmo, porque es el origen del cristianismo y porque la presencia judía ha sido relevante en la historia de España. A los musulmanes, porque esta historia no se entiende sin su contraposición frente al Islam. Y a la Reforma, porque la historia moderna de nuestro catolicismo se entreteje con la del protestantismo y plantea el problema del ecumenismo. Más allá de estas variedades religiosas, la clase de catolicismo habría de incluir un mapa muy general de las formas religiosas del mundo actual.

Ahora bien, esta centralidad del catolicismo no implica monopolio educativo alguno. También hay que respetar a las minorías que cuenten con un número considerable de fieles y asegurarse de que tengan la oportunidad de educarse en su religión, como ha pedido el Consejo de Europa" ${ }^{11}$ Por eso la Ley de Libertad Religiosa de 1980 (art. 7.1) determina que "el Estado, teniendo en cuenta las creencias religiosas existentes en la sociedad española, establecerá, en su caso, Acuerdos o Convenios de cooperación con las Iglesias, Confesiones y Comunidades religiosas inscritas en el Registro que por su ámbito

10 Cf. Orientaciones pastorales, nn. 13-15.

11 Cf. Convenio Marco para la Protección de Minorías Nacionales ( $n .157$ del Consejo de Europa), hecho en Estrasburgo el 1 de febrero de 1995 (art. 12). 
y número de creyentes hayan alcanzado notorio arraigo en España”. Consecuentemente, el Estado español suscribió en 1992 los correspondientes Acuerdos con la comunidad evangélica, el judaísmo y el islam. Así es como estas comunidades religiosas, que no protagonizan nuestra tradición ni, por tanto, nuestra identidad, pueden hoy abrir escuelas en conformidad con un marco legal fiel a los artículos 16.3, 27.3, 27.6 y 27.7 de la Constitución.

Sin embargo, no caigamos en una tolerancia falsa y sensiblera, en la moda actual del diálogo en un "mundo plural e intercultural", como se suele decir. Más que por la multiculturalidad, nuestra sociedad se caracteriza por un olvido de las propias raíces culturales, quedándonos una cultura superficial que tiende fácilmente a sincretismos y relativismos. Teniendo esto en cuenta, los centros caracterizados por una fe distinta de la católica tienen derecho a existir en España, pero la enseñanza de su religión no debería suplantar a la del catolicismo. Por eso, si el hogar y los lugares de culto no bastan para conservar las tradiciones religiosas familiares, los alumnos con otras raíces, o sus padres en la escolarización temprana, tienen que poder elegir una asignatura sobre la religión correspondiente, la cual no debe sustituir a la clase de religión católica. Ésta sí sería obligatoria; aquélla, en cambio, opcional.

La verdadera posibilidad de diálogo y enriquecimiento radica en esta aceptación legal de escuelas con identidades religiosas distintas y en la opción curricular de asignaturas de otras religiones dentro de la escuela pública. Pero siempre contando con la obligatoriedad de la enseñanza del catolicismo. De este modo, a la par que se proporciona una educación "conforme a la cultura y a las tradiciones patrias" también abriremos la escuela "a las relaciones fraternas con otros pueblos" (GE 1).

\section{El absurdo liberal}

Llegados a este punto, es preciso criticar de raíz el planteamiento liberal del problema de la clase de religión. Como el planteamiento mismo es lo que falla, los desacuerdos en torno al problema resultan irrelevantes. Lo que hay que hacer es replantear la cuestión desde la perspectiva correcta. 
Si nos lo tomamos en serio, el liberalismo se anula a sí mismo. Las asignaturas de ciencias no podrían impartirse de forma obligatoria en ninguna etapa de ninguna escuela pública que fuera verdaderamente liberal, porque implican la promoción de una determinada forma de vida: una vida basada en las ciencias, que confía en el uso de la razón, en su aptitud para descubrir la verdad y resolver y allanar las dificultades de la existencia. Por eso la escuela actual no es neutral, pues se considera que el pensamiento científico-técnico es mejor que otros modos de pensar, como el mitológico, el estático-visionario o el mágico ${ }^{12}$. Estoy de acuerdo, pero conste que esto ya es una valoración que rebasa la neutralidad. Con lo cual ya hemos optado por una forma de vida, sencillamente porque el pensamiento racional y sus frutos científicos modernos constituyen nuestra historia y nuestra herencia. Sin duda, necesitamos de ella para seguir siendo quienes somos.

Ahora bien, la neutralidad es imposible no sólo en cuanto a las asignaturas, sino también en relación con el profesor. No hace falta que se equivoque, que falsee el punto de vista o que no acierte a ver lo que desde él se ve. Basta con que sea simplemente un punto de vista, es decir, que se ponga el acento en ciertas cosas y se desatiendan otras, que se tenga especial sensibilidad para lo uno, pero no para lo otro. Los problemas vitales de cada cual, la situación en la que uno se encuentra, las capacidades y los intereses configuran la perspectiva del profesor. Dado que la realidad se nos muestra siempre desde una perspectiva - que es personal y social, biográfica e históricapara ser coherente consigo mismo el liberal no tendrá más remedio que renunciar a la institución escolar; o bien salir de su error y reconocer que la imparcialidad, neutralidad o como se le quiera llamar es una quimera.

La escuela pública no es neutral, ni debe serlo. No es posible ni deseable evitar la promoción de ciertos valores ni dejar de estimular e incitar hacia formas de vida a las que pertenecemos y que estamos llamados a continuar. Lo cierto es que nuestras preferencias más

12 Sobre los diversos modos de pensar, cf. D. A. Yáñez, "La epistemología de la razón histórica", Bajo Palabra 18 (2018) 321-336. 
íntimas nos instan a vivir según ciertas formas. Por eso el liberalismo verdadero será el que proponga la existencia de las instituciones que preferimos. Conste que no se trata de un capricho subjetivo. Pese a que se emplea de forma corriente en su forma verbal, el concepto de "preferencia" constituye aquí un tecnicismo filosófico en el que ahora no conviene profundizar, pero que en modo alguno alude a lo que solemos entender por una mera "cuestión de gustos". Las instituciones preferidas son aquellas dentro de las cuales la vida se pueda desenvolver con libertad: la libertad necesaria para realizar individual y colectivamente nuestros auténticos proyectos de vida, en suma, nuestra vocación ${ }^{13}$. En el caso de nuestra escuela preferida, ésta tiene que incluir una enseñanza obligatoria de catolicismo.

\section{La fe y la cultura de la sociedad actual}

La asignatura de religión católica, tal como la planteo, tiene que cumplir uno de los objetivos más urgentes y reivindicados por la Iglesia: la inculturación de la fe. El cristianismo genuino no es reaccionario; si está vivo, no puede consistir en un vestigio de otro tiempo, no puede quedarse anclado en formas culturales del pasado. Para los cristianos, la humanidad se renueva cada vez que se bebe del agua viva de Cristo (Jn 7,37-39). Con el envío del Espíritu prometido, Él da a los hombres las fuerzas para que la Iglesia se transforme en cada época y que así se ponga a la altura de los tiempos. Esto no puede hacerse sin entrar en diálogo con la cultura del tiempo, la cual, guste o no, constituye la cosmovisión en la que viven los fieles. Es menester hacerse cargo de ella; asumir todo lo que tenga de auténtico para presentar a través de ella una nueva versión del Evangelio. También es necesario que el mensaje cristiano enmiende la superficialidad y el error de toda cultura que no proporcione una verdadera orientación vital y que suma al hombre en la infelicidad, la frivolidad, el egoísmo, el hedonismo y el utilitarismo; en suma, en el dolor innecesario y en la inautenticidad.

13 Cf. J. Ortega y Gasset, Del imperio romano, en Obras Completas, VI, Madrid 2006, 83-132 (en lo que sigue se citará, como es habitual, indicando el tomo con números romanos y las páginas en arábigos). 
"La fe descubre en la cultura actual elementos que, bajo capa de progreso y autonomía, alejan de Dios e implantan nuevas servidumbres y dominaciones del hombre por el hombre" ${ }^{14}$. Por eso la fe cristiana tiene una doble tarea: primero, "ejercer una función crítica mostrando los riesgos de la deshumanización allí latentes"; segundo, lograr "que el Mensaje evangélico aparezca, en su radical autenticidad, como una superación positiva de la rivalidad axiológica que el pensamiento contemporáneo ha establecido entre el hombre y Dios". El Concilio Vaticano II lo dejó claro en Gaudium et spes: "vivan los fieles en una muy estrecha unión con los demás hombres de su tiempo y esfuércense en penetrar su manera de pensar y sentir, cuya expresión es la cultura" (n. 62). De este modo, refiriéndose a la necesaria evangelización de las culturas, Pablo VI ya nos advirtió de que "la ruptura entre el evangelio y la cultura es, sin duda alguna, el drama de nuestro tiempo" (EN 20).

El hombre medio de hoy a menudo ignora la diversidad de géneros literarios de la Biblia y sigue pensando que el progreso alcanzado desmiente las Escrituras: por ejemplo, que la física y la biología refutan el Génesis. A esta supuesta incompatibilidad entre la fe y la ciencia se añade la pretendida superación de la moral cristiana por parte de movimientos feministas y LGTBI de carácter extremista. De esta manera, son muchos los que desconocen el sentido del mensaje cristiano y son muchos los que viven al margen de las exigencia de la fe, pese a estar bautizados e incluso haberse educado en escuelas católicas ${ }^{15}$.

Por su parte, los que se niegan a renunciar al cristianismo tratan de adaptar la antropología teológica de la Iglesia a las nuevas opiniones, que han ido creciendo y que pronto, si no ha ocurrido ya, se convertirán en la nueva opinión pública. Esta adaptación muchas veces consiste simplemente en sumarse a la moda de los tiempos

14 Orientaciones pastorales, n. 39.

15 Problema constatado en documentos importantes como EN 52, Juan Pablo II, Exhortación apostólica postsinodal "Ecclesia in Europa" sobre Jesucristo vivo en su Iglesia y fuente de esperanza para Europa, Ciudad del Vaticano 2003. A partir de ahora EE. En este caso EE 46-47 o Francisco, Evangelii gaudium: Exhortación apostólica sobre el anuncio del Evangelio en el mundo actual, Ciudad del Vaticano 2013. A partir de ahora EG. En este caso EG 14. 
partiendo del desconocimiento de la propia riqueza cultural. Pero, ¿vamos a renunciar al patrimonio de la Tradición de la Iglesia? ¿Cómo va a dialogar la Iglesia con la cultura actual habiendo perdido su identidad?

La Iglesia tiene que poseer su tradición para poder dialogar con la cultura. Después tiene que plasmar en la escuela la inculturación conseguida, en la clase de religión cuando se trata de la escuela pública y en toda la escuela cuando se trata de un centro cristiano. De este modo, la escuela católica tiene la misión de "ordenar últimamente toda la cultura humana según el mensaje de salvación, de suerte que quede iluminado por la fe el conocimiento que los alumnos van adquiriendo del mundo, de la vida y del hombre" (GE 8). Para ello, la asignatura de religión tiene que destacarse sobre las demás enseñanzas escolares al hacerse cargo de todas en la transmisión de un sentido último de la vida $^{16}$. Además, esta inculturación "demanda del profesor unos mínimos conocimientos de las materias esenciales del currículo de otras áreas cuyas aportaciones culturales están en relación con la enseñanza religiosa"17. Por eso es urgente que el profesorado de religión deje de mirarse el ombligo, como suele hacerse en las diversas esferas de la cultura. La imagen del universo se ha fragmentado en compartimentos estancos y la cultura ha

16 "Con todas sus implicaciones éticas", añaden las Orientaciones Pastorales sobre la Enseñanza Religiosa Escolar. Pero conviene aclarar que la religión, aunque incluya una moral, no se reduce a ella. La opinión contraria no es más que el prejuicio ilustrado que predica la racionalidad moderna como superación de la fe, a la que se tacha de mera superstición. Según esta actitud ilustrada, la moral es lo único que antes resistía -hoy ni siquiera eso- cuando se purificaba la religión de sus supersticiones y revestimientos históricos culturales. Claro que la ilustración no es más que una rebeldía adolescente contra la religión y la posible antesala de una fe adulta. Consecuentemente, la elección habitual entre religión y ética en la escuela está mal planteada: al no elegirla se amputa la dimensión estrictamente religiosa de la educación del alumno, en detrimento de la plenitud e integridad de su formación. Con razón leemos en la Constitución, en consonancia con la Declaración Universal de Derechos Humanos (art. 26), que «la educación tendrá por objeto el pleno desarrollo de la personalidad humana» (art. 27.2).

17 Comisión episcopal de enseñanza y catequesis, El profesor de Religión Católica, identidad y misión, Edice, Madrid 1988. 
perdido toda comunicación interior. Tal como está la situación, el profesor de religión tiene la misión de restaurar la integridad del saber para ver el mundo entero desde el punto de vista cristiano. Y no es una tarea fácil, porque los alumnos no carecen únicamente de cultura religiosa. La ignorancia es alarmante en todos los campos: en historia, desconocen su pasado cayendo en tópicos y manipulaciones ideológicas; en literatura, aprenden de memoria sin apenas leer y ni se avergüenzan de ello; en arte, nada les impulsa a ir a un museo y cuando van resbalan la mirada de cuadro en cuadro; en fin, en todas las materias hablan y escriben un español con significados que confunden, palabras desfiguradas por el inglés y un léxico huérfano de muchas palabras en negligente desuso. Como la crisis de identidad no es meramente religiosa, sino total, el profesor de religión lo tendrá muy difícil. Sin colaboración, tendrá que suplir en la medida de lo posible las carencias del resto de disciplinas ${ }^{18}$.

Al que tenga hijos quizá todo esto le parezca exagerado. Se debe a que el desconocimiento de los familiares también es preocupante: en gran medida se ignoran los planes de estudios y los temarios; hay quienes piensan sólo en las calificaciones, sin plantearse nunca qué sentido tiene que sus hijos aprendan una cosa u otra. Muchas veces parece que estudiar sirve sólo para tener un trabajo con el que ganarse la vida: la medida supuestamente objetiva es la nota obtenida. Que los alumnos estudien cosas prácticas, aplicadas y que tengan salidas; que incluyan la informática y las tecnologías. Y que se estudie inglés y algún otro idioma práctico, como el chino (nada de lenguas con pocos hablantes, a no ser que seamos nacionalistas; mucho menos lenguas "muertas", que tanto vivifican).

¿Somos conscientes de que la función de la escuela consiste en educar, es decir, en proporcionar al alumno la cultura que lo humaniza y que lo levanta sobre la mera animalidad? Para cumplir dicha función, como toda institución, la escuela se apoya en las creencias

18 El diagnóstico que en su tiempo hizo Ortega (la barbarie del especialismo) sigue hoy vigente: cf. Ortega y Gasset, Misión de la Universidad, en Obras Completas, IV, 540-541. 
y valoraciones que la sociedad hereda del pasado y que la configuran tal como es. Por eso la enseñanza de la escuela, regulada por el poder político, depende de la legitimidad social que tenga, en función del consenso de creencias y valoraciones de la sociedad. Esto significa que la escuela trata de transmitir a la generación siguiente la cosmovisión de la actual, heredada de las anteriores. La escuela introduce al alumno "en el patrimonio de la cultura conquistado por las generaciones pasadas" (GE 5). Pero no se trata de la mera reproducción de la sociedad actual en el futuro; hay que estimular la imaginación, los deseos, la capacidad sentimental, la curiosidad y todo lo que hace posible la génesis y trasformación de la cultura recibida. De este modo, lo que se tramite nunca es inerte, sino que incita a ir más allá. En vista de la nueva situación vital e histórica de los alumnos respecto de la de las generaciones pasadas, los estudiantes, si se los despierta para ello, reaccionan desde su perspectiva e innovan. En continuidad con el pasado, fabrican una nueva cultura y con ella una nueva vida.

Nadie quitaría las ciencias del currículo escolar, porque la fe en ellas y la conciencia de su utilidad forman parte de la opinión pública vigente. En cambio, la consideración de la religión no goza del mismo prestigio social. Pese que la mayoría de la población española todavía es católica, desde 1999 hasta hoy el número de fieles (y entre ellos, de los practicantes) no ha hecho sino descender ${ }^{19}$. De hecho, durante el comienzo de la reciente pandemia las encuestas del CIS contabilizaron el porcentaje más bajo de católicos en España ${ }^{20}$. Y es así porque se ha ido gestando una nueva opinión pública que está desplazando las ideas y los valores cristianos, que parecen tan sólo vestigios de otros tiempos; politizando las cosas - o lo que es igual, frivolizando-se tildan de supervivencias que interesan a "la derecha". La falta de posesión de la cultura va favoreciendo los relativismos, el saber de oídas un poco de todo y de nada y, sobre todo, la politización automatizada. Sin posibilidad de comprender los problemas de la vida individual y social, se clasifican las opiniones y actitudes, incluidas las religiosas, en polos opuestos de derechas e izquierdas que van absorbiéndolo

19 cf. R. Cruz, "España registra en noviembre el número más bajo de católicos en la historia", Vida Nueva Digital (14-12-2018).

20 cf. R. Cruz, "España pierde la fe en medio del coronavirus", Vida Nueva Digital (16-04-2020). 
todo y poniendo la etiqueta política más odiada al que no comparte el parecer propio. Es la hora del hombre-masa del que hablaba Ortega: un hombre vacío de cultura; por lo mismo, un hombre politizado ${ }^{21}$.

Dado que la sociedad tiende, no sólo a la secularización, sino al secularismo, la pérdida de la legitimidad social de la enseñanza religiosa escolar necesita de la reacción vigorosa de la Iglesia, sobre todo de sus minorías selectas ${ }^{22}$. Me refiero a las altas jerarquías eclesiales en los documentos que publican, a los sacerdotes en sus homilías, a los profesores de religión, teología y ciencias religiosas en las clases que imparten, a los encargados de la catequesis y, en definitiva, a todos los mentados en el ejemplo diario de sus vidas. ¿Quién si no va a orientar a los fieles y a convencer al resto de la sociedad de la importancia de la religión?

La Iglesia no debe desertar de su puesto y amoldarse a los tiempos sin leer sus signos. No debe dejarse arrastrar por cualquier opinión pública, adaptándose a ella para lograr prestigio social. Al contrario, aceptemos la verdad: cualquier doctrina y forma de vida creadora empieza siendo impopular. La minoría selecta tiene a la masa en su contra y tiene que ganársela. Por eso un profeta nunca es bien recibido en su patria $($ Lc 4,24$)$ y la misión que Dios le encomienda es la de profetizar, no simplemente al pueblo, sino contra él (Am 7, 15-16). De ahí que lo que diga el individuo selecto no coincida con la opinión pública - es decir, con la dóxa-, sino que vaya contra ella: que sea, por tanto, paradoxa ${ }^{23}$. Ésa es la misión actual de la Iglesia: ir contra el sentido común, "ser signo de contradicción” (EE 34).

\section{España en Europa}

Como hasta ahora se ha hablado sólo de España, convendría hacer una somera alusión a la enseñanza religiosa en Europa. Excluyo de ante-

21 Cf. Ortega y Gasset, La Rebelión de las masas, en Obras Completas IV, 364-365.

22 Sobre la distinción de minorías, masas y hombres-masa: cf. Ortega y Gasset, España invertebrada, en Obras Completas III; Ortega y Gasset, La Rebelión de las masas, en Obras Completas IV, así como las indicaciones imprescindibles de J. Marías en Acerca de Ortega, Madrid, 1991, 219-249.

23 Cf. Ortega y Gasset, El hombre y la gente, en Obras Completas IX, 398. 
mano todo afán superficial de imitación de lo extranjero que haga caso omiso de la historia y de la realidad social de los demás países. Si miramos a Europa es porque ninguna de sus naciones son tales en soledad. La sociedad española es una variedad europea. Europa es la gran sociedad, el espacio originario de convivencia social del hombre occidental24.

Hay que repetir lo que dijo Juan Pablo II: "no se puede dudar de que la fe cristiana es parte, de manera radical y determinante, de los fundamentos de la cultura europea. En efecto, el cristianismo ha dado forma a Europa, acuñando en ella algunos valores fundamentales" (EE 108). Estas palabras siguen teniendo vigencia: en un momento de crisis como el actual, Europa tiene que reencontrarse a sí misma, tiene que salvar su identidad. ${ }^{25}$ Tiene que hacerlo con la conciencia de que el substrato cristiano de los pueblos occidentales, como dice el papa Francisco, contiene una reserva moral de valores propios del humanismo cristiano ${ }^{26}$. Son esos valores los que el hombre europeo, en sus distintas versiones, ha de "recuperar con fidelidad creativa" 27 . Este patrimonio europeo de valores forma parte de una herencia cultural común de la que empezamos a apropiarnos en la escuela. Por eso, lejos de ser una particularidad española, la enseñanza religiosa es una necesidad continental.

Con frecuencia decimos y oímos que ciertas cosas, normalmente malas, sólo pasan en España. Es la eterna cantinela que ya denunció Larra, parece que sin demasiado éxito, en aquel artículo titulado "En este país..." ${ }^{28}$. El que expresa sus opiniones hablando de ese modo con frecuencia ignora lo que pasa en los demás países, con lo que sus juicios de valor tienen poco valor, aunque calan. Hacen mucho daño en la opinión pública y pocos se atreven a desmentirlos. Hagámoslo aquí con la ERE: no son cosas de España, inexistentes en el resto del continente. Ocurre justo al contrario: prácticamente en toda Europa se enseña religión ${ }^{29}$.

24 Cf. Ortega y Gasset, De Europa meditatio quaedam, en Obras Completas IX, 83.

25 Cf. EE 109.

26 Cf. EG 68.

27 Cf. EE 109.

28 Cf. M. J. De Larra, Artículos de costumbres, Barcelona 1981, 275-283.

29 Cf. C. García de Andoaín, "Enseñanzas de la religión en Europa”, Iglesia viva 261 (2015) 117-126. También: cf. J. G. Stegmann, "El nuevo Gobierno devalúa la asignatura de Religión y viola los acuerdos con la Santa Sede”, ABC (13-01-2020). 
En unos países obligatoriamente, en otros, de forma optativa; en unos casos de modo confesional, incluyendo una o varias confesiones, y en otros, como en Reino Unido, con una perspectiva cultural de 'educación espiritual's0. Francia, salvo Alsacia y Lorena, es la gran excepción. ${ }^{31}$

\section{Epílogo sobre el alma cristiana de la escuela}

En definitiva, hay que tomar conciencia de que la autenticidad del proyecto colectivo español exige la toma de posesión de su herencia cristiana, que comparte con Europa. Si la olvidamos, si renunciamos a ella - con toda su historia, sus conquistas morales, intelectuales y artísticas y el sentido de las muchas fiestas y costumbres que impregnan la sociedad, las sociedades europeas dejarían de ser ellas mismas. Como dijo Juan Pablo II, "los cristianos no sólo pueden unirse a todos los hombres de buena voluntad para trabajar en la construcción de este gran proyecto [europeo], sino que, más aún, están invitados a ser su alma, mostrando el verdadero sentido de la organización de la ciudad terrena" (EE 116).

Si España, como parte de Europa, tiene alma, ¿no tendrá que tenerla también su escuela? ¿No habrá que "dar un alma a la escuela"?² En tal caso sería una escuela verdaderamente liberal, una que actua-

30 A los adoradores de la educación nórdica se les quitarán las ganas de imitarlos en materia religiosa, teniendo en cuenta que en Finlandia, Suecia y Dinamarca la asignatura de religión es obligatoria. Además, Dinamarca y Noruega son estados confesionales cuya Iglesia nacional tiene su cabeza en la Casa Real. Una decepción para los que piensen que la asignatura de religión, junto con la realeza, es una anomalía española heredada del franquismo.

31 Allí la religión se imparte en el horario extraescolar, la enseñanza es más bien pastoral y catequética y no entra dentro el currículo. Es verdad que contamos con tentativas de cambio: el informe de Régis Debray del 2002, en el que se abogaba por una enseñanza del hecho religioso debido a su importancia en la historia, la cultura y los conflictos sociopolíticos actuales. Sin embargo, con François Hollande se prescindió de la asignatura correspondiente, que iba a cursarse a partir de 2012. Más recientemente, aunque el presidente Macron haya reconocido las raíces cristianas de Europa y hoy se alarme del terrorismo islámico, hasta donde yo sé, nada me indica que el gobierno francés vaya a cuestionar su escuela laica.

32 Cf. Benedicto XVI, Discurso a un grupo de profesores de religión en escuelas italianas (25-04-2009). 
lice y potencie en las nuevas generaciones la forma de vida que les corresponde. Hacer realidad esta escuela ideal demandaría una reforma educativa de la ERE en el sentido apuntado a lo largo de estas páginas. Pero, con todo, al lector que estuviera de acuerdo con todas ellas todavía le quedaría una duda, pues nada se ha dicho sobre la confesionalidad de la asignatura. Cerremos este artículo con unas pocas palabras al respecto.

La confesionalidad suele justificarse aduciendo el derecho de los padres a elegir para sus hijos la asignatura de religión. Pero habiendo negado este derecho y distinguido la ERE de la catequesis hace falta otra justificación, a menos que defendamos una asignatura de historia y cultura de las religiones que no esté a cargo de la Iglesia. Sin embargo, si la clase de religión "no se imparte desde una actitud de fe en comunión con la Iglesia" podría convertirse en una "escuela de indiferentismo" en la que se manejen meros datos, sin que el profesor, reducido de teólogo a historiador o sociólogo, transmita de modo adecuado el sentido de la religión ${ }^{33}$. En efecto, ¿quién mejor que un auténtico católico a la hora de explicar lo esencial de su religión? Dado que el creyente confiesa una Verdad que le ha salido al encuentro y que ha aceptado, ¿no habría que dejar que la Iglesia sea la que nos cuente cuál es el mensaje que lleva siglos aceptando, custodiando, interpretando y comunicando?

33 Cf. Orientaciones pastorales, n. 55. 